of its curriculum, continually assessing its performance and making adjustments as warranted. For example, the differential equations course has been revised to include a dynamical systems approach focusing on mathematical models of environmental issues.

Given the passion with which the Bryn Mawr math faculty has built this exemplary program, it will come as no surprise that they are leaders nationally. Rhonda Hughes, working with Sylvia Bozeman, Professor of Mathematics at Spelman College, founded the highly successful and awardwinning EDGE program, a program that supports women and minorities as they make the transition from undergraduate to graduate school. Other faculty have taught in the EDGE program or at the IAS Women and Mathematics Program. In sum, this small faculty, consisting of eight permanent members, has played a national role well out of proportion to its size.
The purpose of the Award for an Exemplary Program or Achievement by a Mathematics Department is to recognize a department that has distinguished itself by undertaking an unusual or particularly effective program of value to the mathematics community, internally or in relation to the rest of society. The department at Bryn Mawr, by playing such a prominent and effective role, both at Bryn Mawr and nationally, in the effort to increase the number of women and students from underrepresented backgrounds who major in math certainly meets these criteria. Further, the department at Bryn Mawr provides a model that may be implemented at other departments with similar demographics and missions. It is for these reasons that the department is so deserving of this award.

\title{
DOCEAMUS
}

—doceamus . . . let us teach

\section{Inquiry-Based Learning: Yesterday and Today}

\section{Ronald G. Douglas}

A little more than fifty years ago, I entered a classroom at the Illinois Institute of Technology (IIT), where I was a freshman, and had an experience that changed my life. The professor, Pasquale Porcelli, was teaching calculus using an inquiry-based approach I learned later was called the Moore Method. In the class we were being asked to develop rigorously the basic concepts of calculus, together with the theorems, along a carefully crafted path developed by him. Moreover, we had to present and defend our ideas to the rest of the class.

Ronald G. Douglas is distinguished professor of mathematics at Texas A\&M University. His email address is rdoug1as@math.tamu .edu.

Members of the Editorial Board for Doceamus are: David Bressoud, Roger Howe, Karen King, William McCallum, and Mark Saul.

DOI: http://dx.doi.org/10.1090/noti836
Over the remainder of my studies at IIT, about half of my mathematics classes were taught in this manner and the other half by the traditional lecture method. Upon graduation I followed Porcelli to Louisiana State University (LSU), where I obtained my doctorate under his direction. Again, about half of my studies at LSU followed the Moore Method approach and half by way of lectures. What were the benefits of the inquiry-based approach to learning and why do I say it changed my life?

While I had been interested in mathematics before, these Moore Method courses prompted me to decide not only to major in mathematics as an undergraduate but also to pursue a doctorate. Further, I found that I understood the basics in most areas and how to approach questions so well that I had a head start in learning new mathematics as well as in doing research. But that was not all. A mastery of clear, critical thinking carried over to 
other parts of my life, including my administrative career. Knowing how to approach problems and defend the value and correctness of my insights and analyses were invaluable in my roles as department chair, dean, provost, and executive vice president, and in a leadership position in the wider mathematics community.

But why am I relating to you this "ancient history" concerning my life and career? After all, it is not surprising that a mathematically talented student such as I was might thrive in the atmosphere of a Moore Method classroom. Let me tell you why.

Several years ago, because of this background, I joined a project to develop and promote approaches to mathematics instruction closely related to the Moore Method-methods which are called inquiry-based learning or IBL. While related in spirit to the Moore Method, IBL is broader and can be characterized as a student-centered approach that focuses on solving, communicating, and discussing meaningful mathematics problems in a purposeful sequence and, further, to construct and understand mathematical concepts. (And constructing a purposeful sequence is critical.)

After several years of effort, the IBL project decided that an impartial, objective evaluation and assessment was needed to determine the effects of IBL at the four universities where the project was focused. The data collected have been tabulated and analyzed, and the results are now available. ${ }^{1}$ They did not surprise or disappoint. First and foremost, there were positive benefits for almost all students. However, two findings were particularly welcome and we believe important.

Women students reported a more positive experience and much greater learning gains in the IBL courses as compared to lecture courses. In particular, whereas the gains in IBL courses were largely independent of gender, that was not the case in lecture courses. Moreover, the same was true for students whose previous performance in mathematics was below average. These students reported a more positive experience and developed a better understanding of mathematics. Finally, we did not see the increasingly negative attitude toward mathematics that was formed by students in the lecture courses!

What lessons can be drawn from these data? I am not suggesting that the data support that all mathematics be taught using an IBL approach. However, having some IBL courses, particularly early in their studies, seems to provide a more positive experience for women students and improves their attitude toward mathematics. It also seems to help below-average-achieving students catch up or, at least, perform at a level which would enable them to go on in mathematics-related disciplines.

$\sqrt[1]{\text { http://www.colorado.edu/eer/research/ }}$ steminquiry.htm1.

MAY 2012

NOTICES OF THE AMS
Now I am not certain my experience at IIT and LSU can be used to evaluate an IBL approach for current students. That is why the evaluation/assessment study is so important. We all seek to use our own experience as a guide to understand what we see in today's classrooms. Sometimes this works and sometimes it doesn't.

Given the great penchant of today's students to communicate their thoughts with each other in "real time", it is not clear to me how that fits with the lecture method. And I doubt that their intense desire to interact with all information sources, as their blogs and constant use of ubiquitous social media make clear, supports the lecture approach either. In particular, it seems to me that an IBL approach would resonate more strongly with today's students.

In evaluating and assessing the various approaches to mathematics instruction, we must be careful that we agree on the goals we have for them. Learning mathematics is certainly most important. But developing a positive attitude toward mathematics and acquiring the ability to learn and use mathematics are key in a student's future studies and career.

In conclusion, I believe the assessment study strongly supports the notion that to achieve these goals for today's students, experiencing an IBL approach in several mathematics courses is superior to a program based only on lectures.

.

-

